\begin{tabular}{|c|c|c|}
\hline \multirow{3}{*}{$\begin{array}{r}\text { Case Reports in } \\
\text { Gastroenterology }\end{array}$} & \multicolumn{2}{|c|}{ Case Rep Gastroenterol 2019;13:299-304 } \\
\hline & $\begin{array}{l}\text { DOI: 10.1159/000501066 } \\
\text { Published online: July 10, } 2019\end{array}$ & $\begin{array}{l}\text { (c) } 2019 \text { The Author(s) } \\
\text { Published by S. Karger AG, Basel } \\
\text { www.karger.com/crg }\end{array}$ \\
\hline & $\begin{array}{l}\text { This article is licensed under } \\
\text { International License (CC BY-^ } \\
\text { Usage and distribution for comn }\end{array}$ & $\begin{array}{l}\text { nons Attribution-NonCommercial } 4.0 \\
\text { ger.com/Services/OpenAccessLicense). } \\
\text { uires written permission. }\end{array}$ \\
\hline
\end{tabular}

\title{
Measurement of Adenosine Deaminase in Ascitic Fluid Contributed to the Diagnosis in a Case of Tuberculous Peritonitis
}

\author{
Kenichi Kishimoto ${ }^{a}$ Tsuyoshi Mishiro $^{\mathrm{a}, \mathrm{b}}$ Hironobu Mikami ${ }^{\mathrm{a}}$ \\ Noritsugu Yamashita ${ }^{a}$ Kazushi Hara $^{c}$ Wataru Hamamoto ${ }^{a}$ Yuumi Cho ${ }^{a}$ \\ Yukihiro Ikuta ${ }^{a}$ Makoto Nagasaki $^{d}$ Yoshikazu Kinoshita ${ }^{b}$ \\ aDepartment of Gastroenterology and Hepatology, National Hospital Organization, \\ Hamada Medical Center, Hamada, Japan; ${ }^{b}$ Department of Internal Medicine II, Faculty of \\ Medicine, Shimane University, Izumo, Japan; 'Department of Surgery, National Hospital \\ Organization, Hamada Medical Center, Hamada, Japan; dDepartment of Pathology, \\ National Hospital Organization, Hamada Medical Center, Hamada, Japan
}

\section{Keywords}

Tuberculous peritonitis · Ascites · Adenosine deaminase

\section{Abstract}

A diagnosis of tuberculous peritonitis (TBP) is difficult because of nonspecific manifestation and limited effectiveness of conventional diagnostic tools. Recently, the usability of measurement of ascitic adenosine deaminase (ADA) was shown. We report here a case of TBP in which measurement of ascitic ADA contributed to the diagnosis. A 93-year-old male developed a large amount of ascites. Analyses of the ascitic fluid revealed exudation, though antibiotics treatment was ineffective. Using paracentesis, the ADA level in the ascites was measured and shown to be high. Under suspicion of TBP, an exploratory laparoscopy was performed and a definitive diagnosis of TBP was made.

(C) 2019 The Author(s)

Published by S. Karger AG, Basel 


\section{Case Reports in Gastroenterology}

Case Rep Gastroenterol 2019;13:299-304

DOI: 10.1159/000501066

c) 2019 The Author(s). Published by S. Karger AG, Basel www.karger.com/crg

Kishimoto et al.: Measurement of Adenosine Deaminase in Ascitic Fluid Contributed to the Diagnosis in a Case of Tuberculous Peritonitis

\section{Introduction}

The peritoneum is one of the most common extrapulmonary sites of tuberculous (TB) infection, with TB peritonitis (TBP) first cared for in a documented case from The New York Hospital in 1843 [1]. Thereafter, introduction of antituberculous chemotherapy and improvements in sanitation led to a decline in all forms of TB, including TBP. Recently, its prevalence has been rising due to the usage of more powerful immunosuppressant therapy, a greater number of HIV-positive individuals, and age-related diminution in immune function. According to a systematic review, TBP occurs in up to $3.5 \%$ of cases of pulmonary TB and comprises $31-58 \%$ of those of abdominal TB involving the esophagus, stomach, intestinal tract, hepatobiliary duct, pancreas, perianal area, and lymph nodes [2]. In Western Europe and North America, an association between TBP and cirrhosis has frequently been described [3, 4]. Other factors, such as chronic renal failure requiring continuous ambulatory peritoneal dialysis and HIV infection, have also been shown to be important risk factors $[5,6]$. However, the diagnosis of this disease is difficult because of a lack of specific clinical features and the limited effectiveness of commonly used diagnostic tests. Isolation of mycobacteria from sampled ascitic fluid is also difficult, thus a laparoscopy is frequently needed for the diagnosis. Meanwhile, the usability of measurement of ascitic fluid adenosine deaminase (ADA) has recently been shown $[7,8]$. Here, we report a case of TBP in which ascitic fluid ADA measurement contributed to the diagnosis.

\section{Case Report}

A 93-year-old male with chronic kidney disease came to our hospital with complaints of nausea, anorexia, and weight loss. Vital signs were unremarkable. A physical examination noted abdominal distension with a fluid wave. Laboratory tests showed normal liver function findings, while renal function was decreased with eGFR at $31.0 \mathrm{~mL} / \mathrm{min} / 1.73 \mathrm{~m}^{2}$. White blood cell count was 3,510/ $\mu \mathrm{L}$, and C-reactive protein level was $5.27 \mathrm{mg} / \mathrm{dL}$. A computed tomography (CT) scan revealed a large amount of ascites, as well as thickened walls of the ascending and transverse colon (Fig. 1a). In the chest, there was a linear scar-like lesion in the apex area of the left lung (Fig. 1b). Abdominal paracentesis was performed, and analyses of ascitic fluid revealed a high total protein level of $5.8 \mathrm{~g} / \mathrm{dL}$ and low serum-ascites albumin gradient (SAAG) of $0.6 \mathrm{~g} / \mathrm{dL}$, suggesting exudative ascites. Furthermore, the white blood cell level in the ascites was above the measurement limit, thus antibiotics treatment (sulbactam/cefoperazone) was started for suspected bacterial peritonitis, though that had a scant effect. Paracentesis was performed again, and ADA in ascitic fluid was measured, which showed a high level of 108.2 U/L (reference range, 8.6-20.5 U/L). That measurement suggested TBP; thus, acid-fast staining and polymerase chain reaction (PCR) testing for Mycobacterium tuberculosis was performed, though those results were negative. To obtain a definitive diagnosis, an exploratory laparoscopy was performed, which revealed extensive, thickened adhesions between the peritoneum, omentum, and bowel. A yellowish-white thickened peritoneum and miliary nodules on the peritoneum were also observed (Fig. 2). Omental and peritoneal biopsy findings showed epithelioid granulomas with Langhans giant cells and infiltrating lymphocytes (Fig. 3 ). The results of 3 consecutive concentrated sputum smear tests for acid-fast bacillus were all negative, and a test for HIV infection was also negative. Treatment began with a 3-drug protocol of rifampicin, ethambutol, and isoniazid, due to reduced renal function. Eight weeks after starting treatment, a mycobacterial culture of obtained tissue was positive for $M$. 


\section{Case Reports in Gastroenterology}

Case Rep Gastroenterol 2019;13:299-304

DOI: 10.1159/000501066

c) 2019 The Author(s). Published by S. Karger AG, Basel www.karger.com/crg

Kishimoto et al.: Measurement of Adenosine Deaminase in Ascitic Fluid Contributed to the Diagnosis in a Case of Tuberculous Peritonitis

tuberculosis. One month later, ascites and associated symptoms were resolved, and the patient was discharged at 4 months after starting treatment.

\section{Discussion}

Peritoneal tuberculosis is reported to occur under 3 different conditions, with the most common reactivation of latent TB foci in the peritoneum established via hematogenous spread from a primary lung focus [9]. The next most common condition is hematogenous spread in the setting of active pulmonary $\mathrm{TB}$ or miliary $\mathrm{TB}$, and the third condition is entrance into the peritoneal cavity in a transmural manner from an infected small intestine or via contiguous spread from TB salpingitis [10]. In our patient, chest CT imaging showed a linear scar-like lesion in the apex area of the left lung, which was considered likely to have a tuberculoid origin. This is consistent with speculations noted in past studies that TBP is usually secondary to hematogenous spread from a pulmonary focus.

Clinical manifestations of TBP are nonspecific, though affected patients in previous reports have often presented with ascites (93\%), abdominal pain (73\%), and fever (58\%) [11]. The ascites in these cases is often exudative, with a SAAG $<1.1 \mathrm{~g} / \mathrm{dL}$ [2]. The present patient as well had a low SAAG value. His chief complaints of nausea and anorexia were considered to be due to ascites.

A diagnosis of abdominal TB is definitively established by demonstration of $M$. tuberculosis in peritoneal fluid or a biopsy specimen from an involved site, such as the peritoneum, intestine, or liver. However, the sensitivity of acid-fast staining $(<2 \%)$ and mycobacterial culturing of ascitic fluid $(<20 \%)$ is low, while results of liquid-based cultures are not available for at least 2-3 weeks, and solid egg-based culture results require $4-8$ weeks $[12,13]$. The utility of ascitic fluid PCR for the diagnosis of TBP has been reported [14], though it has not been well established. In the present patient, the results of acid-fast staining, mycobacterial culturing of ascites, and PCR were all negative. However, TBP cannot be denied even if these tests are not positive. Furthermore, Chow et al. [11] reported that TBP-associated mortality is high among patients waiting for results of mycobacterial cultures of ascitic fluid samples.

Measurement of ADA has been reported to be useful for the evaluation of patients with suspected TBP and to be the most reliable marker in the absence of cirrhosis [7, 8]. A metaanalysis found that ADA levels had high sensitivity (100\%) and specificity $(97 \%)$ when using a cutoff value of 36-40 U/L [7]. On the other hand, in patients with cirrhosis, the sensitivity of ADA measurement in ascitic fluid is only approximately $30 \%$, likely due to poor humoral and $\mathrm{T}$ cell-mediated responses [15]. The ADA level in our patient was 108.2 U/L, much greater than reported cutoff values, which supported the diagnosis.

To obtain a definitive diagnosis, we performed a laparoscopic peritoneal biopsy, as the diagnostic yield of a laparoscopic examination is very high with sensitivity of the macroscopic appearance approaching 93\% [2]. With disease progression, the peritoneum becomes studded with tubercles and ascites development for exudation of proteinaceous fluid from the tubercles is shown, which can be observed as thickened peritoneum with yellowish-white lesions.

As seen in the present case, diagnosis of TBP can be difficult. Nevertheless, it is important to consider TBP as a differential diagnosis in patients with ascites of unknown etiology and measure the ADA level. For a definitive diagnosis, an exploratory laparoscopy should be performed for patients with nondefinite diagnostic ascites analysis findings. 


\section{Case Reports in Gastroenterology}

Kishimoto et al.: Measurement of Adenosine Deaminase in Ascitic Fluid Contributed to the Diagnosis in a Case of Tuberculous Peritonitis

\section{Statement of Ethics}

Written informed consent was obtained from the patient for publication of this case report and any accompanying images.

\section{Disclosure Statement}

None of the authors have any financial conflicts of interest. All authors have confirmed that the article is not under consideration for review at any other journal.

\section{Funding Sources}

The authors have no funding sources.

\section{Author Contributions}

All authors have made contributions to the article and have reviewed it before submission.

\section{References}

1 Dineeen P, Homan WP, Grafe WR. Tuberculous peritonitis: 43 years' experience in diagnosis and treatment. Ann Surg. 1976 Dec;184(6):717-22.

2 Sanai FM, Bzeizi KI. Systematic review: tuberculous peritonitis-presenting features, diagnostic strategies and treatment. Aliment Pharmacol Ther. 2005 Oct;22(8):685-700.

3 Shakil AO, Korula J, Kanel GC, Murray NG, Reynolds TB. Diagnostic features of tuberculous peritonitis in the absence and presence of chronic liver disease: a case control study. Am J Med. 1996 Feb;100(2):179-85.

4 Aguado JM, Pons F, Casafont F, San Miguel G, Valle R. Tuberculous peritonitis: a study comparing cirrhotic and noncirrhotic patients. J Clin Gastroenterol. 1990 Oct;12(5):550-4.

5 Lui SL, Tang S, Li FK, Choy BY, Chan TM, Lo WK, et al. Tuberculosis infection in Chinese patients undergoing continuous ambulatory peritoneal dialysis. Am J Kidney Dis. 2001 Nov;38(5):1055-60.

6 Al Shohaib S. Tuberculosis in chronic renal failure in Jeddah. J Infect. 2000 Mar;40(2):150-3.

7 Riquelme A, Calvo M, Salech F, Valderrama S, Pattillo A, Arellano M, et al. Value of adenosine deaminase (ADA) in ascitic fluid for the diagnosis of tuberculous peritonitis: a meta-analysis. J Clin Gastroenterol. 2006 Sep;40(8):705-10.

8 Tao L, Ning HJ, Nie HM, Guo XY, Qin SY, Jiang HX. Diagnostic value of adenosine deaminase in ascites for tuberculosis ascites: a meta-analysis. Diagn Microbiol Infect Dis. 2014 May;79(1):102-7.

9 Mehta JB, Dutt A, Harvill L, Mathews KM. Epidemiology of extrapulmonary tuberculosis. A comparative analysis with pre-AIDS era. Chest. 1991 May;99(5):1134-8.

10 Tang LC, Cho HK, Wong Taam VC. Atypical presentation of female genital tract tuberculosis. Eur J Obstet Gynecol Reprod Biol. 1984 Jul;17(5):355-63.

11 Chow KM, Chow VC, Hung LC, Wong SM, Szeto CC. Tuberculous peritonitis-associated mortality is high among patients waiting for the results of mycobacterial cultures of ascitic fluid samples. Clin Infect Dis. 2002 Aug;35(4):409-13.

12 Marshall JB. Tuberculosis of the gastrointestinal tract and peritoneum. Am J Gastroenterol. 1993 Jul;88(7):989-99.

13 Chow KM, Chow VC, Szeto CC. Indication for peritoneal biopsy in tuberculous peritonitis. Am J Surg. 2003 Jun;185(6):567-73.

14 Uzunkoy A, Harma M, Harma M. Diagnosis of abdominal tuberculosis: experience from 11 cases and review of the literature. World J Gastroenterol. 2004 Dec;10(24):3647-9.

15 Huang HJ, Yang J, Huang YC, Pan HY, Wang H, Ren ZC. Diagnostic feature of tuberculous peritonitis in patients with cirrhosis: A matched case-control study. Exp Ther Med. 2014 Apr;7(4):1028-32. 


\section{Case Reports in Gastroenterology}

\begin{tabular}{l|l}
\hline Case Rep Gastroenterol 2019;13:299-304 \\
\hline DOI: 10.1159/000501066 & $\begin{array}{l}\text { @ 2019 The Author(s). Published by S. Karger AG, Basel } \\
\text { www.karger.com/crg }\end{array}$ \\
\hline
\end{tabular}
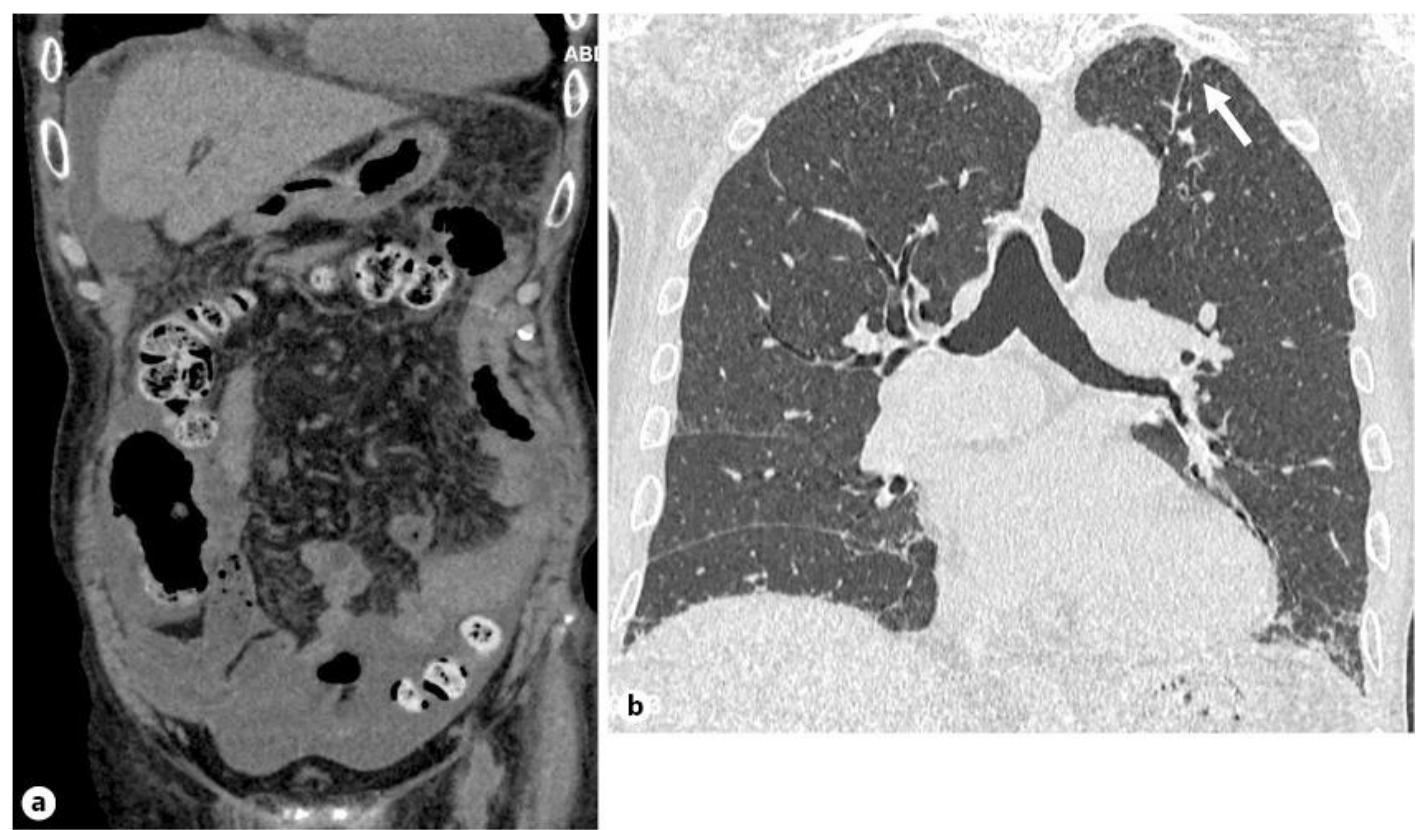

Fig. 1. a Computed tomography (CT) image of the abdomen showed a large amount of ascites, as well as thickened walls of the ascending and transverse colon. $\mathbf{b}$ Chest CT image showing a linear scar-like lesion in the apex area of the left lung (arrow).

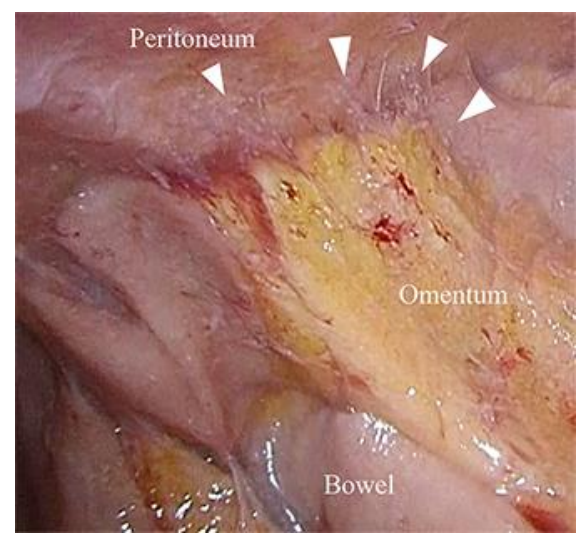

Fig. 2. Exploratory laparoscopy findings showing extensive, thickened adhesions between the peritoneum, omentum, and bowel. Furthermore, a yellowish-white thickened peritoneum and miliary nodules (arrowheads) on the peritoneum were also revealed. 


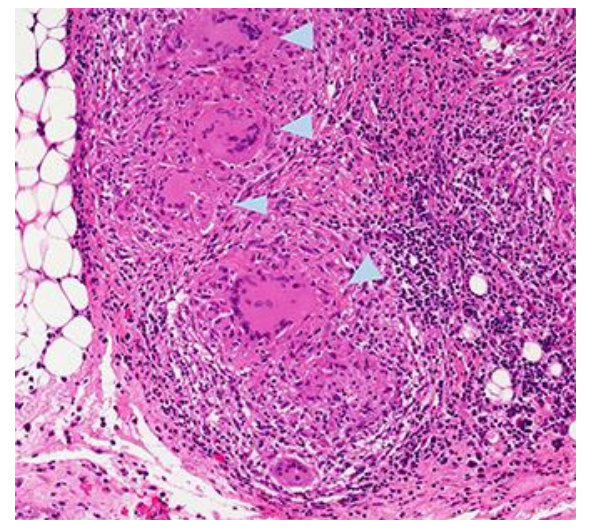

Fig. 3. Omental and peritoneal biopsy results showing epithelioid granulomas with Langhans giant cells (arrowheads) and infiltrating lymphocytes (HE staining; $\times 100$ ).

Kishimoto et al. Measurement of Adenosine Deaminase in Ascitic Fluid Contributed to the Diagnosis in a Case of Tuberculous Peritonitis 